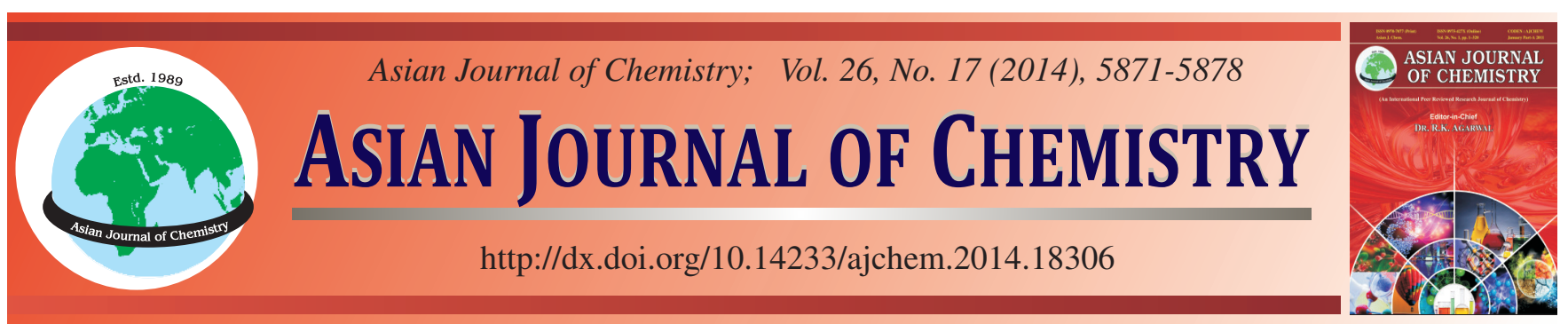

\title{
Effect of Surface Roughness of Al5052/CFRP Composites on Adhesion and Mechanical Properties $\dagger$
}

\author{
M.S. LEE ${ }^{1}$, S.J. KIM ${ }^{1}$, O.D. Lim $^{2}$ and C.G. KANG ${ }^{1, *}$
}

${ }^{1}$ School of Mechanical Engineering, Pusan National University, Pusan 609-735, Republic of Korea

${ }^{2}$ R \& D Center, Autogen Co., Ltd., 180, Okgucheondong-ro, Siheung-si, Gyeonggi-do, 429-849, Republic of Korea

*Corresponding author: Fax: +82 515181456; Tel: +82 515101455; E-mail: cgkang@pusan.ac.kr

\begin{abstract}
In this study, Al5052/CFRP composites were fabricated for an automobile component by compression molding process inside a U-channel mold. Al5052 sheet was treated by sand blasting with two different particle sizes. Accordingly, surface roughness $\left(R_{a}\right)$ values of 4.25 and $1.85 \mu \mathrm{m}$ were obtained for the treated A15052 sheets. The effect of surface roughness of A15052 sheets on the adhesion and mechanical properties of A15052/CFRP composites have been evaluated. Shear lap test and 3-point bending test were conducted. Results showed that the shear load for the composite fabricated by using the treated Al5052 sheets with $\mathrm{R}_{\mathrm{a}}$ value of 1.85 and $4.25 \mu \mathrm{m}$ were three and five times higher than $\mathrm{R}_{\mathrm{a}}$ value of $0.73 \mu \mathrm{m}$ of the composite fabricated by using the untreated sheet. The bending stress of $200 \mathrm{MPa}$ was obtained for the composite fabricated with untreated A15052 sheets. The bending stress increased to 400MPa when the composite fabricated from treated sheets. However, the bending stress was not influenced by treating a condition through sand blasting.
\end{abstract}

Keywords: Hybrid composite materials, U-Channel molding, Surface roughness, Porosity, Carbon fiber reinforced plastic.

\section{INTRODUCTION}

A recent research trend in the automobile industry is the development of robust, light weight and eco-friendly raw materials that can ensure enhanced safety and fuel efficiency in vehicles, as well as help to reduce emissions from vehicles. Some of these studies are focused on the development of advanced high-strength steel (AHSS)-based hot-press-formed components for automobile parts ${ }^{1,2}$.

Meanwhile, studies are also being carried out on electric and fuel-cell vehicles. However, such vehicles tend to be heavier than traditional vehicles due to additional components such as electric motors, supplementary batteries and fuel cells installed in them. There are weight-related limits in technological advancements with the currently available high-tensile steel materials. The development of futuristic vehicles requires the use of considerably light materials with higher specific strength and stiffness than currently used steel materials.

The demand for light weight materials in the automobile industry has given rise to the development and application of composite materials such as carbon fiber reinforced plastic (CFRP), besides high-strength aluminum alloy and magnesium.
Carbon fiber reinforced plastic, particularly, has been attracting great interest owing to its superior characteristics, including strength and stiffness ${ }^{3,4}$. However, CFRP composites have limitations for automotive applications due to their drawbacks of low elongation and fracture toughness, as well as weak bonding between different materials. To overcome such limitations of single-component materials, a study on hybrid composites is currently underway that aims at facilitating welding by mixing CFRP with metallic materials ${ }^{5}$.

The mechanical properties of hybrid composites largely depend on the extent of adhesion achievable between the component materials. Insufficient bonding between different materials lowers crash energy absorption. Furthermore, it is essential to subject CFRP-aluminum (CFRP-Al) junction to a chemical treatment such as etching treatment using phosphoric acid and anodizing prior to bonding ${ }^{6}$, because galvanic effect is likely to accelerate corrosion of aluminum, resulting in the detachment of the junction between CFRP and aluminum. Therefore, extensive research has been carried out to improve the bonding strength between different materials. Al-Zubaidy et $a l .{ }^{7}$ evaluated the bonding strength of steel-CFRP composites. Chung et al. ${ }^{8}$ studied the mechanical properties of 
aluminum foam and CFRP. Furthermore, Rhee $^{9}$ treated the surface of T-peel with plasma, enhancing its bonding strength six-fold and shear strength by $33 \%$. However, aluminum surface treatments, such as chemical etching and plasma treatment, involve high costs, making the mass production of automobile parts using such treatment methods economically infeasible. Therefore, it is crucial to develop a cost-effective surface treatment technology. Furthermore, studies to investigate mechanical properties and adhesion behaviours based on $R_{a}$ value and epoxy infiltration rate are required. $R_{a}$ value is the average surface roughness obtained through physical surface treatment. There is also a lack of research on the singlecomponent epoxy infiltration method for the production of morphologically heterogeneous hybrid composites and thickness homogeneity.

The objective of this study was to find the optimal temperature and pressure conditions for the development of CFRP. Bending test was performed to evaluate the mechanical properties of U-channel hybrid composite materials. $\mathrm{R}_{\mathrm{a}}$ values were measured to evaluate the sandblast surface treatment of aluminum. The effects of surface roughness on the epoxy infiltration rate and thickness were investigated by measuring the weight per cent of epoxy resin and thinning rate.

\section{EXPERIMENTAL}

Production condition for CFRP: The CFRP sheet used in this study was $0.25 \mathrm{~mm}$ thick with epoxy comprising 35 $40 \%$ of the total weight. The properties of the epoxy are listed in Table-1. Before production of Al5052/CFRP/A15052 sandwich composites, to examine effect of process parameters on CFRP, samples with five sheets of CFRP were stacked and heated on a hot plate for $0.5 \mathrm{~h}$ at different pressures and temperatures. Fig. 1 shows the tensile strength of CFRP according to curing temperature and pressure. Fig. 1(a) and (b) show $140{ }^{\circ} \mathrm{C}$ and 0.4 MPa were chosen for the test specimens. The tensile strength was greatest above $0.4 \mathrm{MPa}$ at $140^{\circ} \mathrm{C}$. Fig. 1 (b) shows the high tensile strength at 0.4 and $1.2 \mathrm{MPa}$ at $140^{\circ} \mathrm{C}$. However, during specimen production, although the tensile test was favorable for specimens produced under 1.2 MPa, epoxy spilled out and spread to the die. Consequently, the specimen thickness decreased and while the tensile strength was high, the loss of epoxy resulted in a decrease in interfacial strength between CFRP laminate. Therefore, the specimen was produced at $0.4 \mathrm{MPa}$ as the suitable pressure.

\begin{tabular}{ccc}
\multicolumn{3}{c}{ TABLE-1 } \\
& RESIN PROPERTIES \\
\hline Item & YD-115J & Test method \\
\hline EEW (g/eq) & $175-194$ & KD-AS-001 \\
Viscosity (cps at $25^{\circ} \mathrm{C}$ ) & $150-500$ & KD-AS-005 \\
Hy-Cl (wt. \%) & $0.6-0.9$ & KD-AS-010 \\
Specific gravity & 1.14 & KD-AS-040 \\
\hline
\end{tabular}

Fig. 2 shows the microstructure of CFRP specimens produced under different pressures. These microstructures show why the tensile strength of specimens produced under 0.04 $\mathrm{MPa}$ was lower than 0.4 and $1.2 \mathrm{MPa}$. When $\mathrm{P}_{\mathrm{p}}=0.04 \mathrm{MPa}$, several pores of 30-40 $\mu \mathrm{m}$ occurred as shown in Fig. 2(a). When $\mathrm{P}_{\mathrm{p}}=0.4$ and $1.2 \mathrm{MPa}$, the number of pores decreased

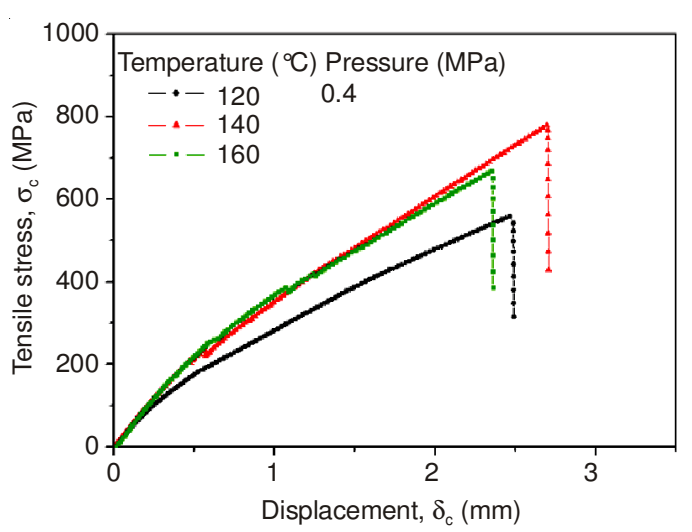

(a) Tensile strength according to curing temperature

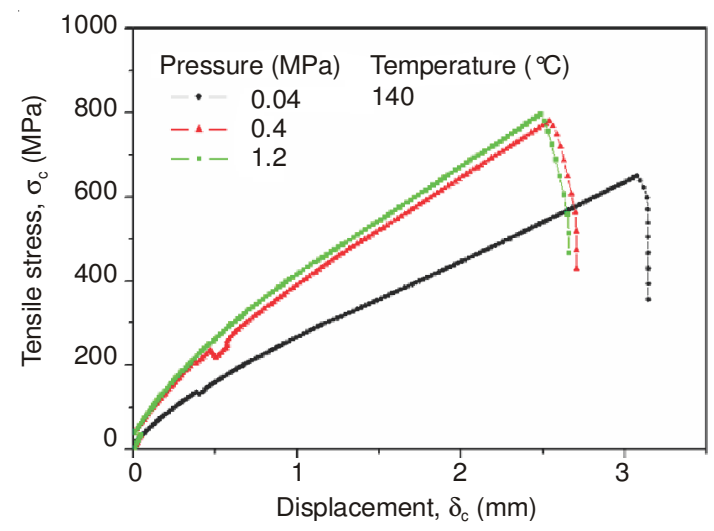

(b) Tensile strength according to pressure

Fig. 1. Curve of tensile stress and displacement according to temperature and pressure

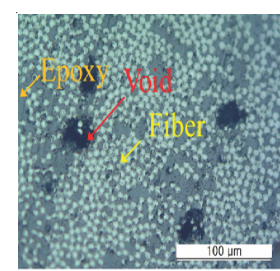

(a) $0.04 \mathrm{MPa}$

Fig. 2. Mic

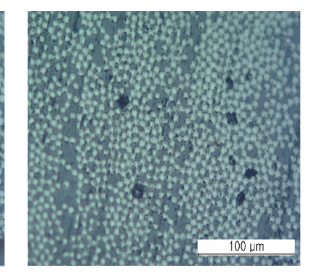

(b) $0.4 \mathrm{MPa}$

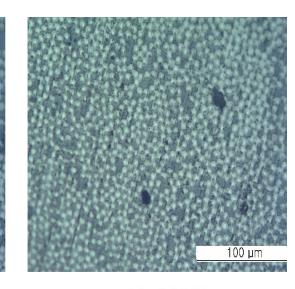

(c) $1.2 \mathrm{MPa}$ and their size decreased to $10 \mu \mathrm{m}$. Zhu et al. ${ }^{11}$ reported that when pressure was higher than $0.4 \mathrm{MPa}$, porosity became less than $1 \%$ and did not affect mechanical properties.

Shear lap test: A15052 materials have excellent welding properties and are thus widely used for the production of automobile components. A $0.5 \mathrm{~mm}$ thick A15052 sheet was used in the shear lap test. The mechanical properties of the sheet are listed in Table- 2 .

\begin{tabular}{cccc}
\multicolumn{4}{c}{ TABLE-2 } \\
& \multicolumn{1}{c}{ PROPERTIES OF AL5052 } \\
\hline $\begin{array}{c}\text { Tensile strength } \\
(\mathrm{MPa})\end{array}$ & $\begin{array}{c}\text { Elongation } \\
(\%)\end{array}$ & $\begin{array}{c}\text { Brinell } \\
\text { hardness }\left(\mathrm{H}_{\mathrm{b}}\right)\end{array}$ & $\begin{array}{c}\text { Elastic modulus } \\
(\mathrm{MPa})\end{array}$ \\
\hline 230 & $12-16$ & 60 & 70 \\
\hline
\end{tabular}

Fig. 3 shows the cross-section of the bonded interface between the Al5052 sheet and the CFRP with and without sand blasting. To prevent galvanic corrosion of aluminum due to the bonding of different materials, its surface was pretreated 


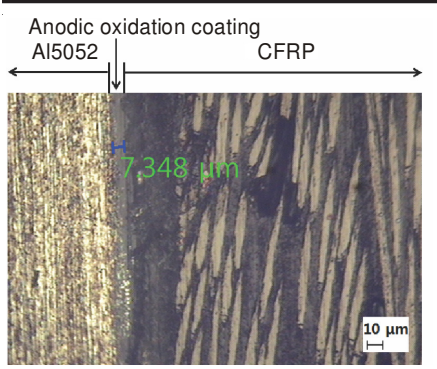

Without sandblasting

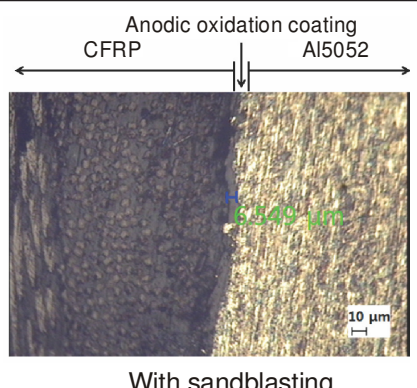

With sandblasting
Fig. 3. Cross-section of A15052 sheet with anodic oxidation coating

with sand blasting, followed by the application of a thin $(<10$ $\mu \mathrm{m})$, flexible anodic oxidation coating.

Fig. 4 is the schematic diagram of the experiment. As shown in Fig. 4(a), both surfaces of the aluminum sheet were pretreated with sand blasting and anodic oxidation coating was applied to them, for enhancing the strength of bonding between different materials. To analyze the effect of $R_{a}$ values on shear strength, specimens were fabricated by bonding a $10 \mathrm{~mm}$ CFRP with a $100 \mathrm{~mm}$ long and $25 \mathrm{~mm}$ wide Al5052 sheet. As shown in Fig. 4(b) and (c), specimens for the shear lap test were fabricated by performing compression molding for $0.5 \mathrm{~h}$ under $0.4 \mathrm{MPa}$ in a flat-type die heated to $140{ }^{\circ} \mathrm{C}$ using a cartridge heater.

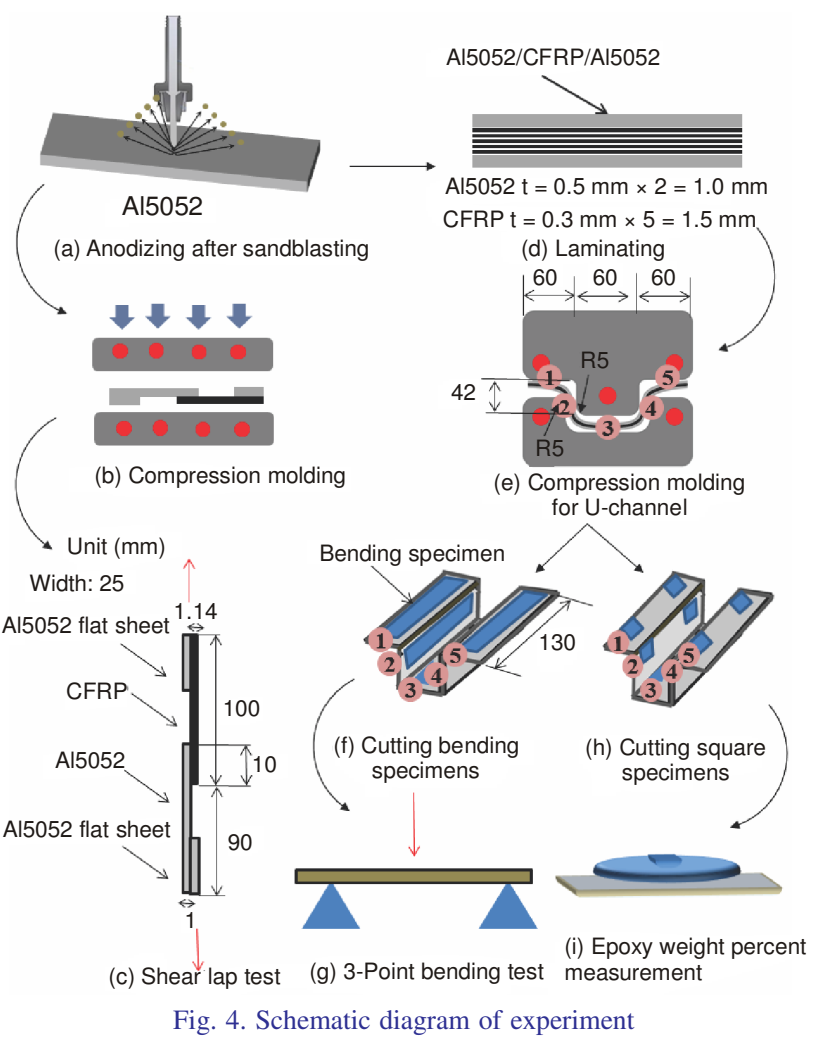

The shear lap test was performed under the MTS conditions of $20 \mathrm{~mm} / \mathrm{min}$, by attaching the aluminum flat sheet to the grip part in a flat position. The test was repeated thrice and the middle value of the three tests, i.e., excluding the highest and lowest values, was taken.

U-channel compression molding: U-channel compression molding experiments were performed to investigate the mechanical properties of A15052/CFRP/A15052 composite and the $\mathrm{R}_{\mathrm{a}}$-dependent effects of the epoxy flow. Specimens of the hybrid composite were prepared by employing the following steps. As illustrated in Fig. 4(d), specimens of Al5052/CFRP/ Al5052 composite were fabricated by sandwiching five 0.3$\mathrm{mm}$ thick CFRP sheets with two $0.5-\mathrm{mm}$ thick sandblastsurface-treated A15052 sheets. This way, specimens with total thickness of $2.5 \mathrm{~mm}(0.3 \mathrm{~mm} \times 5+0.5 \mathrm{~mm} \times 2)$ were formed. The width and length of the Al5052 sheet was 130 and 180 mm, respectively.

As shown in Fig. 4(e), U-channel compression molding of the Al5052/CFRP/A15052 composite was performed for $0.5 \mathrm{~h}$ under pressure of $0.4 \mathrm{MPa}$ in a die heated to $140^{\circ} \mathrm{C}$ with a cartridge heater. This study is a groundwork aiming at developing a technology enabling a mass production process for automobile components. Zhu et al. ${ }^{11}$ reported that voids disappeared almost completely at pressures of $0.4 \mathrm{MPa}$. In this study, specimens were fabricated through high-pressure compression molding and their physical properties were tested to evaluate if they can be used for the mass production of automobile components.

While flat positions 1, 3 and 5 can be squeezed by a punch in the compression molding process, punch force cannot be applied to vertical positions 2 and 4 . Considering this, the punch-die clearance was maintained at 0.7 by setting the tolerance at $1.85 \mathrm{~mm}$. The specimen was thicker $(2.5 \mathrm{~mm})$ than the tolerance of the die (1.85). Therefore, a forceful pressure was applied to the specimen during compression molding.

Once the fabrication of the specimens was completed, bending specimens were cut out at positions 1 through 5, as illustrated in Fig. 4(f), to test the $\mathrm{R}_{\mathrm{a}}$-dependent mechanical properties and interfacial adhesion. The bending specimens were of the size $75 \mathrm{~mm} \times 15 \mathrm{~mm}$, matching the span length and compliant with ASTM (D 790-03) standard ${ }^{10}$. As shown in Fig. 4(g), a three-point bending test was performed at $\mathrm{V}_{\mathrm{f}}=$ $10 \mathrm{~mm} / \mathrm{min}$. Flexural stress was then calculated using eqn. 1,

$$
\sigma_{\mathrm{f}}=\frac{3 P L}{\mathrm{bt}^{2}}
$$

where $\mathrm{P}, \mathrm{L}, \mathrm{b}$ and $\mathrm{t}$ denote flexural load, span length, width and thickness, respectively.

As shown in Fig. 4(h), after evaluating the mechanical properties of five pairs of symmetrically cut square specimens of size $10 \mathrm{~mm} \times 10 \mathrm{~mm}$, at positions 1 through 5 , their $\mathrm{R}_{\mathrm{a}}$-dependent epoxy flows and weight per cent values were measured. As shown in Fig. 4(i), the epoxy amount-dependent epoxy flow was evaluated by comparing the pre-molding and post-molding epoxy weight percents using a scale. The epoxy weight per cent of each square specimen was then calculated using eqn. 2 ,

$$
\mathrm{W}_{\mathrm{r}}=\frac{\rho_{\mathrm{r}} \mathrm{V}_{\mathrm{r}}}{\rho_{\mathrm{r}} \mathrm{V}_{\mathrm{r}}+\rho_{\mathrm{f}}\left(1-\mathrm{V}_{\mathrm{f}}\right)} \times 100
$$

where $\mathrm{W}_{\mathrm{r}}, \rho_{\mathrm{r}}, \rho_{\mathrm{f}}, \mathrm{V}_{\mathrm{r}}$ and $\mathrm{V}_{\mathrm{f}}$ denote epoxy weight per cent, epoxy density, CFRP density, epoxy volume and CFRP volume, respectively.

The change in thickness of each specimen, which depended on their corresponding epoxy weight per cent, was calculated using eqn. 3 . 


$$
\gamma=\frac{\mathrm{t}_{\mathrm{o}}-\mathrm{t}}{\mathrm{t}_{\mathrm{o}}} \times 100
$$

where $\gamma, t_{0}$ and $t$ denote thinning rate, pre-mold thickness and post-mold thickness, respectively.

\section{RESULTS AND DISCUSSION}

Surface treatment with sand blasting: Unlike ionic plasma etching, sand blasting is a sputtering-based physical etching method, wherein atoms or molecules are detached from the surface of the material-A15052, in case of this study-by transferring kinetic energy from an abrasive particle aspirated by air pressure. This kind of physical etching yields the same results as ionic etching.

The $R_{a}$ value of the surface of A15052 varies depending on the size of the abrasive particle. The increase in the $R_{a}$ value is proportional to the increase in the size of the abrasive particle and vice-versa, due to the detachment of same-sized aluminum surface particle.

Fig. 5 shows the images of the surface profiles of sand blast-treated or untreated aluminum specimens. The images were captured using an atomic force microscope (AFM). Table-3 outlines the conditions for the AFM observations.

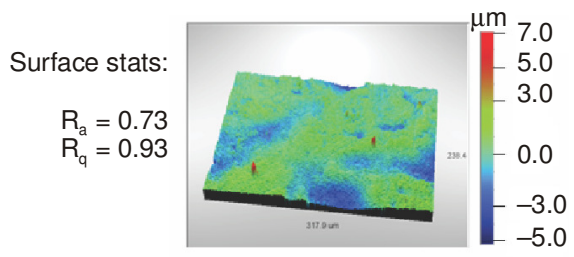

(a) Untreated $R_{a}=0.73$

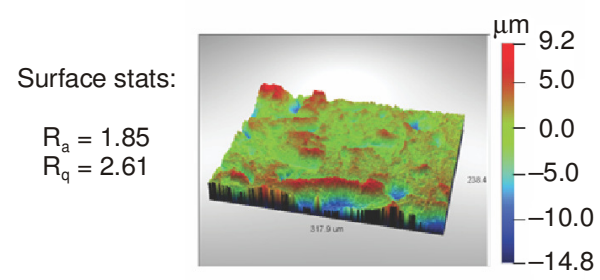

(b) Treated $R_{a}=1.85$

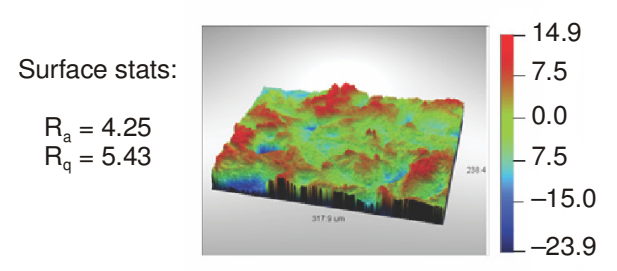

(c) Treated $R_{a}=4.25$

Fig. 5. 3-Dimensional interactive display according to surface roughness with sand blasting

\begin{tabular}{cccc}
\multicolumn{4}{c}{ TABLE-3 } \\
EXPERIMENTAL CONDITION FOR AFM TEST \\
AND AFM EXPERIMENTAL MACHINE \\
\hline \multirow{2}{*}{ Magnification } & $\begin{array}{c}\text { Measurement } \\
\text { mode }\end{array}$ & $\begin{array}{c}\text { Sampling } \\
(\mathrm{nm})\end{array}$ & $\begin{array}{c}\text { Array size } \\
(\mu \mathrm{m})\end{array}$ \\
\hline 20 & VSI & 496.74 & $640 \times 480$ \\
\hline
\end{tabular}

As shown in Fig. 5(a), the $\mathrm{R}_{\mathrm{a}}$ value of an untreated specimen was found to be $0.73 \mu \mathrm{m}$ and the surface profile of the specimen hardly showed any marked differences, except for a few spots. Fig. 5(b) and (c) show the AFM images of the sandblast-treated specimens with $R_{a}$ values of 1.85 and $4.25 \mu \mathrm{m}$, respectively. From the results of the sand blast treatment, it can be concluded that the $\mathrm{R}_{\mathrm{a}}$ value is directly proportional to the deviation in the surface roughness of aluminum. $R_{a}$ values of 0.731 .85 and $4.25 \mu \mathrm{m}$ yielded $\mathrm{R}_{\mathrm{q}}$ values of $0.93,2.61$ and $5.43 \mu \mathrm{m}$, respectively. $\mathrm{R}_{\mathrm{q}}$ is the square roots of mean peak-to-valley distances.

Fig. 6(a) through (c) represent surface roughness through a two-dimensional chart, in which the $\mathrm{x}$-axis denotes the surface roughness. As shown in Fig. 6(a), the untreated specimen with $R_{a}$ value of $0.73 \mu \mathrm{m}$ yielded the $R_{p}$ (highest peak) value of $1.40 \mu \mathrm{m}$ and the $\mathrm{R}_{\mathrm{v}}$ (lowest valley) value of $-1.86 \mu \mathrm{m}$. Fig. 6 (b) and (c), representing the sandblast-treated surface profiles, show that the increase in the $R_{a}$ value from 1.85 to $4.25 \mu \mathrm{m}$ yielded the increase in the $R_{p}$ value from 3.71 to $6.76 \mu \mathrm{m}$ and the decrease in the $R_{v}$ value from $-5.25 \mu \mathrm{m}$ to $-8.59 \mu \mathrm{m}$. The epoxy infiltration volume increases with the increase in the sizes of the detached aluminum particles, due to the increase in the $R_{t}$ value. The $R_{t}$ value increased from 1.40-8.97 $\mu \mathrm{m}$ and then to $15.35 \mu \mathrm{m}$, with the increase in the $\mathrm{R}_{\mathrm{a}}$ value from 0.73 to 1.85 and then to $4.25 \mu \mathrm{m}$, respectively.
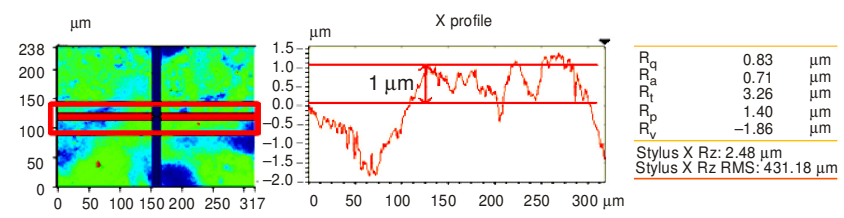

(a) Untreated $R_{a}=0.73$
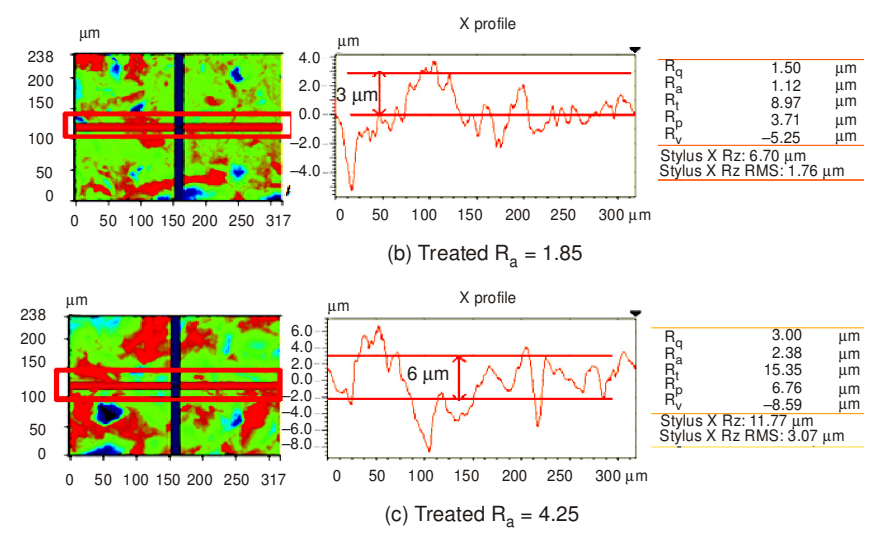

Fig. 6. Roughness of 2-dimensional line section with sand blasting

Shear lap test according to surface roughness: Fig. 7 illustrates displacement graphs of shear load and surface roughness. Shear load was applied until an Al-CFRP specimen, with a $10 \mathrm{~mm}$ lap joint, failed. While the untreated specimen with $R_{a}$ value of $0.73 \mu \mathrm{m}$ showed clean disjointed surfaces, the sandblast-treated aluminum surfaces were left with considerable amounts of epoxy due to greater surface roughness. It was found that with the increase in the roughness of the surface, the volume of infiltrated epoxy left on the aluminum contact surface after failure also increased. The maximum shear load increased from 900 to $3,000 \mathrm{~N}$ and then to $5,000 \mathrm{~N}$, while the displacement rose from 0.5 to $0.8 \mathrm{~mm}$ and then to $1.27 \mathrm{~mm}$. Meanwhile, the $\mathrm{R}_{\mathrm{a}}$ value jumped from $0.73 \mu \mathrm{m}$ (untreated) to $1.85 \mu \mathrm{m}$ and then to $4.24 \mu \mathrm{m}$ (surface-treated), demonstrating 


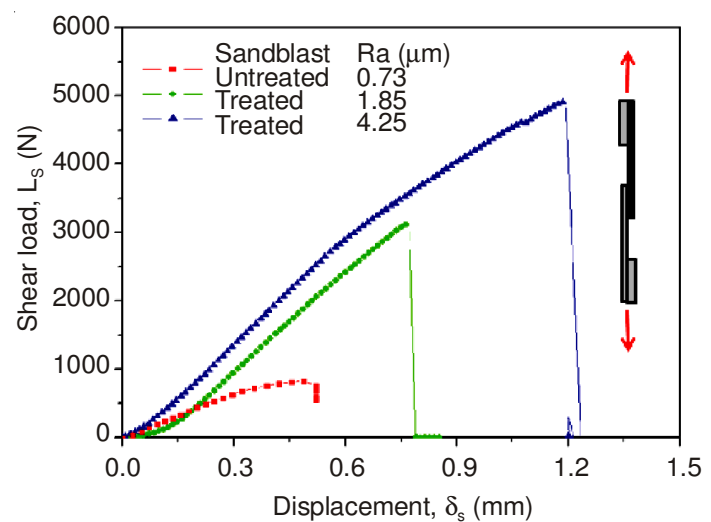

Fig. 7. Shear load and displacement according to surface roughness

three- and five-fold increases in maximum shear loads, respectively.

Flexural stress according to surface roughness: Fig. 8(a) through (c) illustrate the relationship between the positiondependent flexural stress and the displacement of the Uchannel specimens, depending on surface roughness. As shown in Fig. 8(a), the flexural stress of the untreated specimen was found to be about $500 \mathrm{MPa}$ at flat positions 1, 3 and 5 and as low as 150-200 MPa at vertical positions 2 and 4. In contrast, the surface-treated specimens with $\mathrm{R}_{\mathrm{a}}$ value of 1.85 and 4.25 $\mu \mathrm{m}$ demonstrated a considerable increase, in flexural stress to $400 \mathrm{MPa}$, at positions 2 and 4, as shown in Fig. 8(b) and (c). While it was observed that the sideward flexural stress of the surface-treated specimens was twice that of the untreated specimen, the flexural stress at flat positions 1, 3 and 5 did not reach the level of the untreated specimens. The weaker adhesion of the untreated specimen at positions 2 and 4 with respect to positions 1, 3 and 5 was due to the lack of application of pressure at the vertical positions, unlike at the flat positions. Unlike shear load, no $\mathrm{R}_{\mathrm{a}}$-dependent differences were observed in the flexural stress of the two surface-treated specimens at positions 2 and 4 .

Fig. 9 illustrates the $\mathrm{R}_{\mathrm{a}}$-dependent mechanisms of the delamination of the specimens under shear and flexural loads. The $\mathrm{R}_{\mathrm{a}}$ value and CFRP epoxy infiltration of the surface-treated Al5052 specimens are positively related. As shown in Fig. 9(a) and (b), the higher the $\mathrm{R}_{\mathrm{a}}$ value, the greater is the resistance by the infiltrated epoxy against delamination, when the specimen is exposed to shear load. On the other hand, when flexural load is applied vertically, no deep-infiltrated epoxy is observed, as shown in Fig. 9(c) and (d). This explains the insignificant Ra-dependent differences in the flexural loads at the vertical positions, as shown in Fig. 8(b) and (c), unlike shear load, which increased proportionally with the increase in the $R_{a}$ value, as shown in Fig. 7.

Fig. 10 shows the side views, by position and $R_{a}$ value, of the bending specimens after the bending test. At all positions, 1 through 5, one bending side of the untreated specimen was detached after the bending test. Furthermore, while both surfacetreated specimens resisted the bending test at positions 1,3 and 5 , they got detached at positions 2 and 4 . This concludes that the bonding of the interfaces at vertical positions 2 and 4 is weaker than the adhesion at flat positions 1, 3 and 5, even after the sand blast-surface treatment.

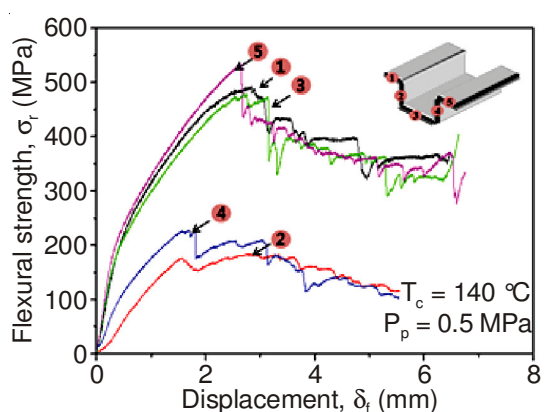

(a) Untreated $R_{a}=0.73$

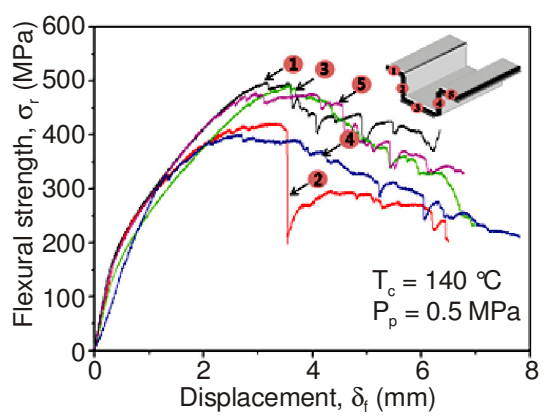

(b) Treated $\mathrm{R}_{\mathrm{a}}=1.85$

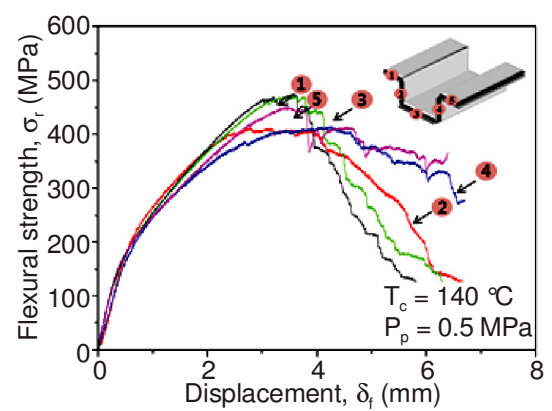

(c) Treated $R_{a}=4.25$

Fig. 8. Correlation flexural stress and displacement according to surface roughness

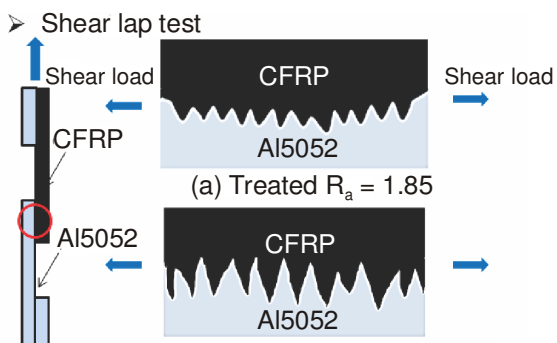

$\checkmark$

(b) Treated $R_{a}=4.25$

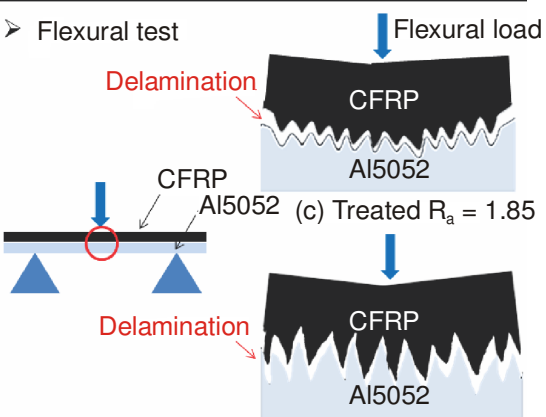

(d) Treated $R_{a}=4.25$

Fig. 9. Mechanism according to surface roughness in shear lap test and flexural test 

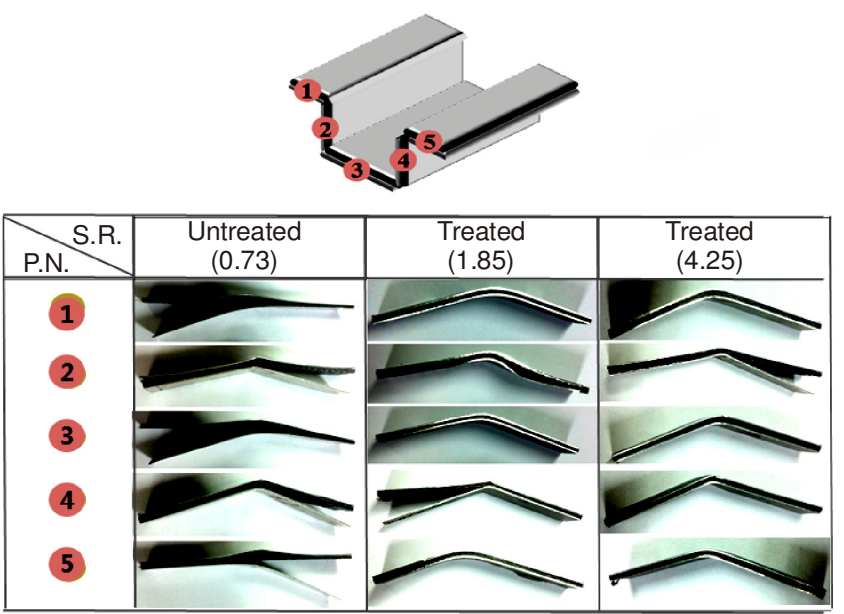

*S.R.: Surface roughness, PN.: Position number

Fig. 10. Side view of bending specimens after bending test according to surface roughness

Fig. 11 shows the microstructure of the bending specimens, by position, after the bending test. The compression molding was expected to leave few voids ${ }^{11}$ because the process was performed under a pressure of $0.4 \mathrm{MPa}$. However, voids of size $30-40 \mu \mathrm{m}$ occurred at positions 2 and 4 due to the lack of continuously applied pressure, while there was no evidence of any void at positions 1, 3 and 5. The voids generated at vertical positions 2 and 4 were assumed to be the cause of deteriorated mechanical properties.
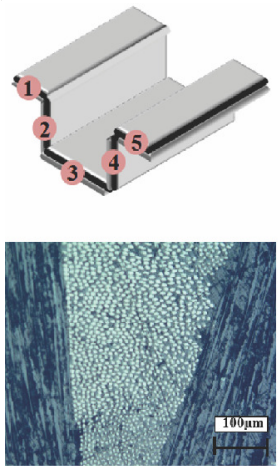

(c) No. 3

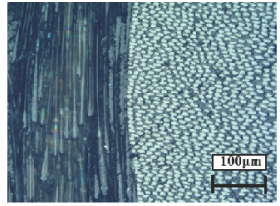

(a) No. 1

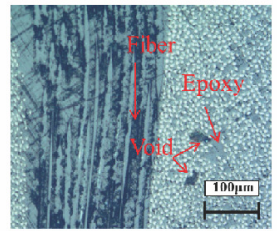

(d) No. 4

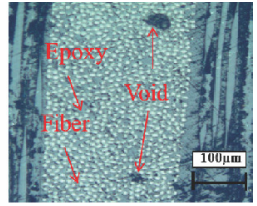

(b) No. 2

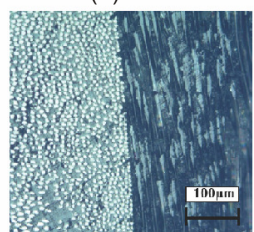

(e) No. 5
Fig. 11. Microstructure of bending specimens after bending test

Epoxy weight per cent and thinning rate: The initial epoxy weight per cent of prepreg is $35 \%$ and that of the Al5052-sandwiched specimen is $16.7 \%$. Fig. 12 shows the $\mathrm{R}_{\mathrm{a}}$-dependent weight per cent at each position. The epoxy weight percents at vertical positions 2 and 4 of the untreated specimen were found to be 5 and $7 \%$, respectively. A large amount of epoxy leaked out of the die during the molding process due to the clearance of 0.7 between the punch and the lower die. The epoxy weight percents at flat positions 1 and 5, after the molding process, were found to be 11 and $11.5 \%$, respectively. This was due to the compression-induced leakage of the epoxy from the die. Position 3 showed the highest epoxy weight per cent of $15 \%$ as the leaked epoxy was compensated by the epoxy inflow induced by gravity. This resulted in a decrease of $1.7 \%$ in the epoxy weight per cent at position 3 from the initial epoxy weight per cent.

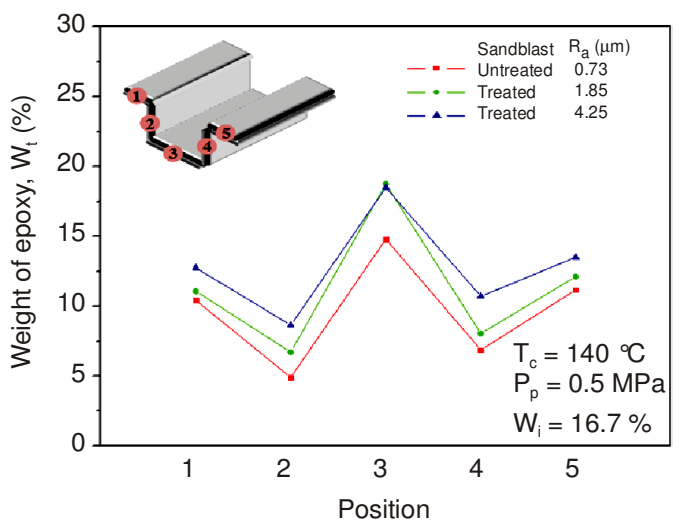

Fig. 12. Epoxy weight percent according to surface roughness

Surface roughness and epoxy weight per cent were found to be positively related at all positions, 1 through 5. At position 3 , the epoxy weight per cent of the untreated specimen with $R_{a}$ value of $0.73 \mu \mathrm{m}$ and the sandblast-treated specimen with $R_{a}$ value of $4.25 \mu \mathrm{m}$ were found to be 15 and $18.7 \%$, respectively, both higher than the initial epoxy weight per cent of $16.7 \%$. This implies that as the roughness of the aluminum surface increases, the area of the aluminum-epoxy interface increases and the epoxy infiltrates deeper across the aluminum surface. At all positions, the epoxy weight per cent increased with the increase in the $\mathrm{R}_{\mathrm{a}}$ value, demonstrating that an increase in surface roughness increases the epoxy weight per cent.

Fig. 13 shows the $\mathrm{R}_{\mathrm{a}}$-dependent thinning rates. The thinning rates at vertical positions 2 and 4 of the untreated specimen with $R_{a}$ value of $0.73 \mu \mathrm{m}$ are 18.2 and $17.5 \%$, respectively. High thinning rates at the vertical positions were results of high amount of epoxy leakages at them. Position 3, which was found to exhibit the highest epoxy weight per cent, showed the lowest thinning rate.

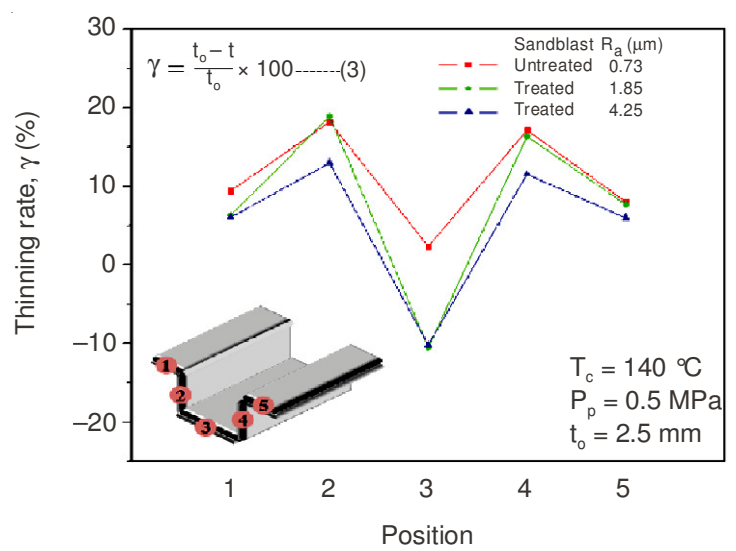

Fig. 13. Thinning rate according to surface roughness

It was found that surface roughness was positively related with epoxy weight per cent, but negatively related with thinning rate. Particularly, at position 3, while the thinning rate was $2.3 \%$ at the $R_{a}$ value of $0.73 \mu \mathrm{m}$, it was $-10.2 \%$ at the $R_{a}$ value of $4.25 \mu \mathrm{m}$, i.e., the thinning rate decreased with the increase in the $R_{a}$ value. The decrease in the thinning rate was due to the increase in the epoxy weight per cent. As shown in Fig. 8, the post-molding epoxy weight per cent was found to be more than the initial or pre-molding epoxy weight per cent. Given 
that epoxy flow influences thickness, it is necessary to evaluate and control epoxy flow behaviour to maintain uniform thickness.

Consideration of defect volume through X-ray computed tomography: Fig. 14 shows X-ray computed tomography (CT) of specimens after the bending test according to surface roughness. X-ray CT data was obtained after the Al5052 was removed. Porosity was $0.5-1.2 \%$ irrespective of surface roughness. The porosity data show that hot compression molding method was highly effective for fabricating A15052/CFRP/ Al5052 composites without autoclaving using a vacuum process. Zhu et al. ${ }^{11}$ reported that CFRP composites presented good mechanical properties when the porosity was less than $1 \%$. Defect volumes were generally $0.1-0.8 \mathrm{~mm}^{3}$. Some defect volumes of $0.2-0.5 \mathrm{~mm}^{3}$ were observed in the untreated specimen as shown in Fig. 14(a). The number and volume of defects increased with increasing surface roughness. Particularly, when surface roughness was $1.2 \mu \mathrm{m}$ as shown in Fig. 14(c), the number and volume of defects was larger than in the other specimens and many defects of $0.4-0.6 \mathrm{~mm}^{3}$ were distributed. This phenomenon might have occurred because the high surface roughness of the A15052 impinged on the CFRP surface and epoxy was removed along with the A15052. The porosity of the CFRP surface increased for this reason. However, porosity of $1.2 \%$ was satisfactory and surface defects were only slightly higher than in other specimens. It is possible to surmise that the internal defects of the 3 specimens [Fig. 14 $(\mathrm{a}-\mathrm{c})]$ were nearly the same.

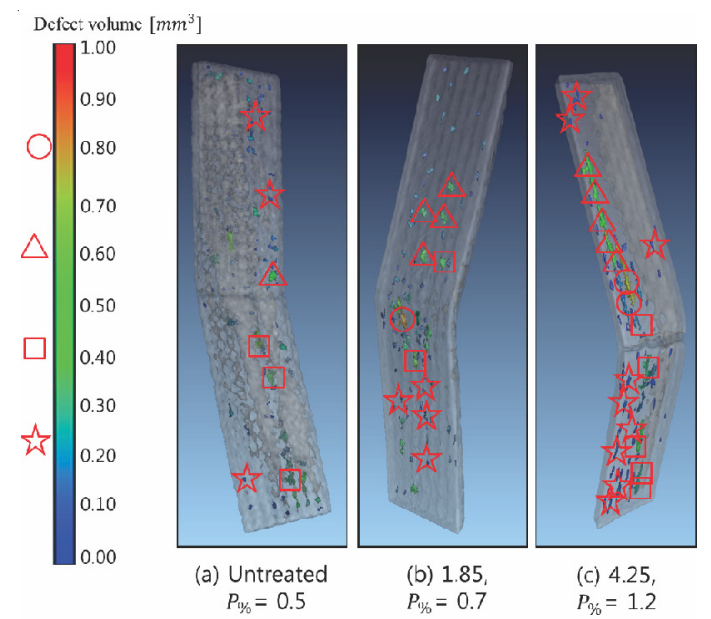

Fig. 14. X-Ray computed tomography (CT) of specimens after bending test according to surface roughness

Fig. 15 shows that X-ray CT data of specimens after bending test according to position number. When position numbers were $1,3,5$, porosities were $1.2,1.1$ and $0.9 \%$, respectively. However, porosity of side position was $2.4-3.2 \%$ (Position number 2, 4) as shown in microstructure (Fig. 11), because enough pressure was not applied to these positions. These porosities were higher than $1 \%$ and high porosity was reason of low mechanical properties as shown in Fig. 8.

Fig. 16 shows numerical data of defect volume obtained through X-ray CT of the specimens. The numerical data of specimens with position number 1,3 and 5 had a similar trend. However, number of the volume of $0.05-7 \mathrm{~mm}^{3}$ defects were

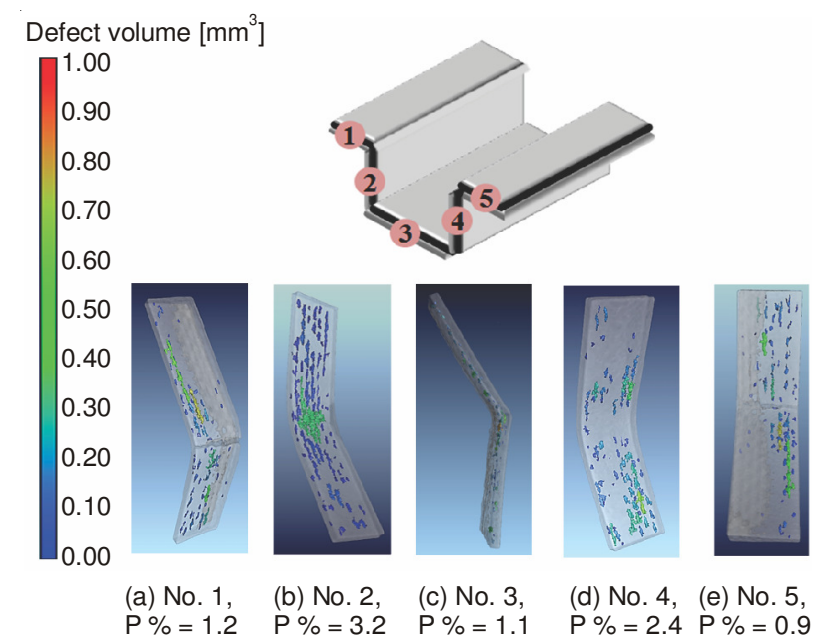

Fig. 15. X-Ray CT data of specimens after bending test according to position number

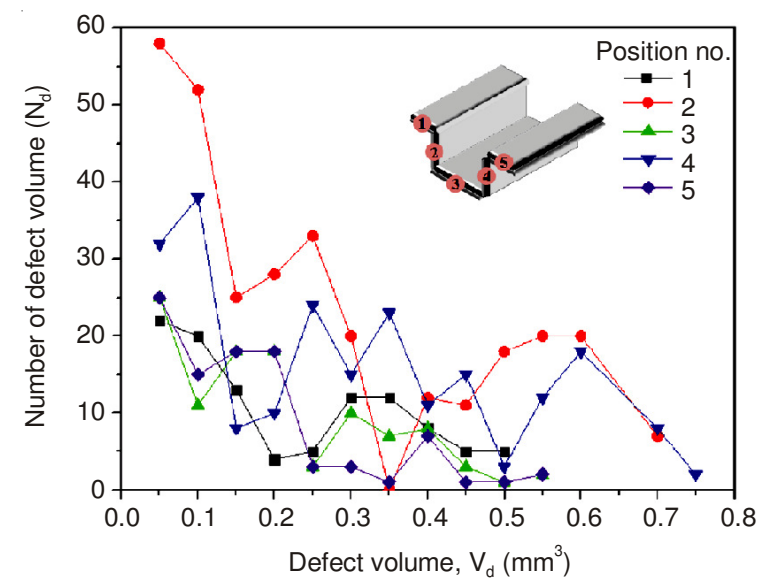

Fig. 16. Numerical data of defect volume obtained through X-ray CT of the specimens

more than the defect volume of other positions at side positions (position number 2 and 4), generally. The numerical data from the X-ray CT results accorded closely with X-ray CT of CFRP according to position numbers as shown in Fig. 15.

\section{Conclusion}

-With the increase in surface roughness, aluminum-epoxy interface increases, resulting in considerable increase in shear load. The sand blast-surface-treated specimens with $\mathrm{R}_{\mathrm{a}}$ values of 1.85 and $4.25 \mu \mathrm{m}$ yielded three- and five-fold shear loads, respectively.

- The flexural stress of the untreated specimen in vertical positions 2 and 4 was as low as $150-200 \mathrm{MPa}$, while that of the surface-treated specimens increased to $400 \mathrm{MPa}$.

- The higher the $\mathrm{R}_{\mathrm{a}}$ value, the deeper is the epoxy infiltration and the higher is the post-molding volume of epoxy. The increase in the volume of epoxy infiltration resulted in the increase in thickness. Thus, to maintain uniform thickness, it is necessary to control epoxy flow.

- As surface roughness was higher, the number and volume of defects was larger and many defects volumes were distributed on surface of CFRP. Mechanical properties were satisfactory at position number 1,3 and 5 , when porosity was around $1 \%$ but when porosity was higher than $1 \%$, mechanical properties were affected at side position. 


\section{ACKNOWLEDGEMENTS}

This study was supported by the Advanced Technology Center Project (10039031, The Development of the Manufacturing Process for the High Strength Steel and Composite Materials) funded by the Ministry of Knowledge Economy (MKE, Korea) and National Research Foundation of Korea (NRF) grant funded by the Korea Government (MSIP) through GCRC-SOP (No. 2011-0030013).

\section{REFERENCES}

1. F.G. Caballero, C. García-mateo, C. Capdevila and C.G. Andrés, Mater. Manuf. Process., 22, 502 (2007).

2. D.W. Fan, H.S. Kim and B.C. De Cooman, Steel Res. Int., 80, 241 (2009).

3. H. AL-Zubaidy, X.-L. Zhao and R. Al-Mihaidi, Proceedia Eng., 10, 2453 (2011)
4. W. Van Paepegem, K. De Geyter, P. Vanhooymissen and J. Degrieck, Compos. Struct., 72, 212 (2006).

5. T. Yu, D. Fernando, J.G. Teng and X.L. Zhao, Composites Part B, 43, 2279 (2012).

6. W.-X. Wang, Y. Takao and T. Matsubara, Galvanic Corrosion-Resistant Carbon Fiber Metal Laminates, 16th International Conference On Composite Materials, Japan, Kyoto, July (2007).

7. H. Al-Zubaidy, R. Al-Mahaidi and X.-L. Zhao, Compos. Struct., 94, 510 (2012)

8. H.J. Chung, K.Y. Rhee, B. Lee and J.H. Lee, J. Alloys Comp., 481, 214 (2009).

9. K. Rhee, Compos. Sci. Technol., 63, 33 (2003).

10. ASTM International, Standard Test Methods for Flexural Properties of Unreinforced and Reinforced Plastics and Electrical Insulating Materials, D 790-03.

11. H. Zhu, B. Wu, D. Li, D. Zhang and Y. Chen, J. Mater. Sci. Technol., 27, 69 (2011) 